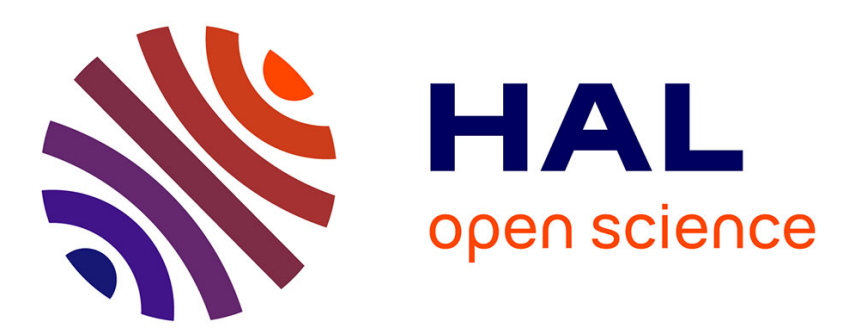

\title{
Scenarios with an intensive contribution of nuclear energy to the world energy supply
}

H. Nifenecker, D. Heuer, S. David, J.M. Loiseaux, J.M. Martin, O. Meplan, A.

Nuttin

\section{- To cite this version:}

H. Nifenecker, D. Heuer, S. David, J.M. Loiseaux, J.M. Martin, et al.. Scenarios with an intensive contribution of nuclear energy to the world energy supply. International Conference on Back-End of the Fuel Cycle: From Research to Solutions (GLOBAL 2001), Sep 2001, Paris, France. 047-(8 p.). in2p3-00011018

\author{
HAL Id: in2p3-00011018 \\ https://hal.in2p3.fr/in2p3-00011018
}

Submitted on 17 Jan 2002

HAL is a multi-disciplinary open access archive for the deposit and dissemination of scientific research documents, whether they are published or not. The documents may come from teaching and research institutions in France or abroad, or from public or private research centers.
L'archive ouverte pluridisciplinaire HAL, est destinée au dépôt et à la diffusion de documents scientifiques de niveau recherche, publiés ou non, émanant des établissements d'enseignement et de recherche français ou étrangers, des laboratoires publics ou privés. 


\title{
SCENARIOS WITH AN INTENSIVE CONTRIBUTION OF NUCLEAR ENERGY TO THE WORLD ENERGY SUPPLY
}

\author{
H.Nifenecker ${ }^{1}$, D.Heuer ${ }^{1}$, S.David ${ }^{1}$, J.M.Loiseaux ${ }^{1}$, J.M.Martin ${ }^{2}$, O.Meplan ${ }^{1}$,A.Nuttin ${ }^{1}$ \\ ${ }^{1}$ Institut des Sciences Nucléaires (IN2P3,UJF) 53 ave. Des Martyrs F38026 Grenoble France \\ ${ }^{2}$ Institut d'Economie et de Politique de l'Energie, BP47, F38040 Grenoble Cedex 09 France
}

\begin{abstract}
Temperature stabilization requires that $\mathrm{CO} 2$ emissions be limited to less than $3 \mathrm{Gt}$ Carbon equivalent, from the present level of more than $6 \mathrm{Gt}$. Despite an increase of primary energy demand by $250 \%$ in 2050 we find that a nuclear intensive scenario assuming the development of a $3000 \mathrm{GWe}$ pool of PWR reactors by 2030 and of an additional $6000 \mathrm{GWe}$ pool of U-Pu or Th-U reactors by 2050 would lead to temperature stabilization at a level 2 degrees above the pre-industrial level.
\end{abstract}

Keywords: Energy scenarios, nuclear power, Plutonium breeders, U3 breeders, Molten salt reactors

\section{1-INTRODUCTION}

The signs of an already present global warming have been summarized and stressed by a recent IPCC ${ }^{1}$ report. As can be seen on Figure1, climatic models show that the atmospheric concentration of Carbon Dioxide, and, thus, the temperature, could be stabilized only if annual anthropic emissions were reduced from the present level of 6 $\mathrm{Gt}^{2}$ to $3 \mathrm{Gt}$ Carbon equivalent. The later this reduced emission rate is reached, the higher the level of $\mathrm{CO} 2$ concentration and, thus, the average world temperature will be.
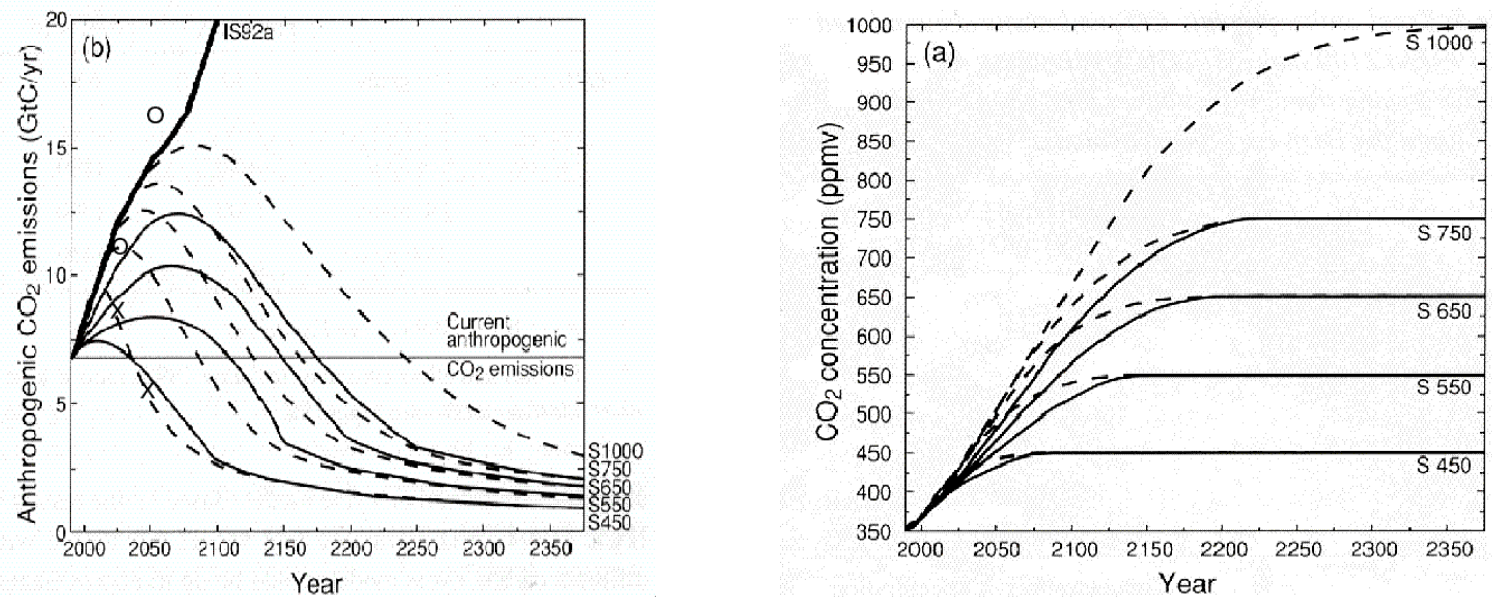

Figure 1 Examples of anthropogenic CO2 emission patterns(left (b)). The curves are labeled by the asymptotic $\mathrm{CO} 2$ concentrations. Full and dashed lines correspond to different patterns leading to the same concentrations. The same concentration is obtained if the area below the curves are the same. Crosses refer to emissions by our scenario, circles to the IIASA A2 scenario. The evolutions of the CO2 concentration are shown on the right(a). From ref.2

By 2050 the world population should lie between 9 and 11 billion, as compared to the present 6 billion. Therefore, in order to stabilize the Carbon Dioxide concentration, a reduction of the average per capita emission by at least a factor of 3 has to be achieved. Thus, the present average $\mathrm{CO} 2$ per capita emission of 1 ton equivalent Carbon should be reduced to 0.3 tons. The actual reduction factor will depend on the emission level of individual countries. For example the US emit about 6 tons per capita, 20 times more than the target average! That we are not moving in the right direction is demonstrated by the projections of the IIASA-WEC report: emissions in 2050 range between $5 \mathrm{Gt}$ in the most "ecological" scenario and $15 \mathrm{Gt}$ in the most "industrial" one.

Strong steps should be taken as soon as possible to decrease greenhouse gas emissions. Due to the le gitimate needs of developing countries, energy demand is bound to increase. Significant reductions of the use of fossil fuels for transportation will be difficult to achieve due to the absence of competitive alternatives to combustion engines at the industrial level. Electricity production amounts to almost $40 \%$ of the primary energy supply ${ }^{\mathrm{i}}$, mostly

\footnotetext{
${ }^{i}$ Here, as well as in the whole contribution, electricity is estimated by the amount of oil necessary to produce it with an efficiency of $30 \%$ (including transport losses). Thus we use the equivalence $1 \mathrm{Twh}=0.3 \mathrm{Mtoe}$
} 
obtained from fossil fuels. Examples such as those of France and Sweden show that this needs not be the case. Using different mixes of hydro and nuclear power, these countries produce their electricity with almost no $\mathrm{CO} 2$ emission. The efficiency of such a policy to reduce greenhouse gas emissions can be evaluated by comparing Denmark and France, two countries with equivalent development levels. For each TOE of primary energy consumed, Denmark releases 3.2 tons of Carbon Dioxide in the atmosphere as compared to 1.6 for France. A significant reduction of the contribution of fossil fuels to the production of electricity is, probably, the most efficient and easy way to start decreasing $\mathrm{CO} 2$ emissions. New renewable energies (wind and solar) are still not competitive. Hydroelectric resources are limited in industrialized countries. They are significant in Asia, Africa and Latin America but their implementation encounters environmental limits. In addition, they are very capital intensive, and this may limit their extension in developing countries. As shown in a recent French study ${ }^{3}$, nuclear power is competitive with fossil fuels for the production of electricity if the complete life cycle ${ }^{\mathrm{ii}}$ is considered.

Usual World energy scenarios only foresee a rather modest contribution of nuclear energy to the future energy mix. For example, in its most nuclear intensive scenario, the World Energy Council limits the contribution of nuclear energy in 2050 , to $15 \%$ iii from the present $5 \%$. On the other hand, the most "ecologically driven" scenarios consider an increase of the contribution of renewable energies from the present $18 \%$ (mostly traditional use of wood and hydroelectricity) $\mathbf{b}$ as much as $37 \%$ in 2050 . This increase is significantly due to the development of wind and solar energies whose present contributions are very small. Like nuclear power, these energies would contribute to mitigating global warming and the exhaustion of fossil reserves. However, they are still much more expensive and capital intensive than nuclear power. Furthermore they require some inexpensive and convenient means of storing electricity and this is still not available today. There is no rational base on which to exclude exploring a larger contribution of nuclear energy than is presently done. This paper gives a preliminary approach to a nuclear intensive scenario.

We first examine in some detail a possible scenario up to year 2030. Indeed, given the inertia of energy producing systems, it seems that important technological breakthroughs would not have time to be applied at the required scale before that year. Our driving motivation is to reduce greenhouse gas emissions as much as possible and we believe that, for the time being, the only large scale alternative is to replace fossil fuel electric power facilities with nuclear ones. However it should be clear that, in our mind, renewable energies could, progressively, replace nuclear power as they become competitive. The important goal is to reduce $\mathrm{CO} 2$ emissions, not to increase nuclear power!

We show that the $3 \mathrm{Gt}$ emission target cannot be reached as early as 2030, and that further progress is needed. Between 2030 and 2050 new technologies may become available on a large scale, especially in transportation, with electric or hydrogen fueled vehicles. Here the new technologies will require additional electricity. For the production of electricity, it should be possible to almost completely exclude the use of fossil fuels, and resort either to nuclear or to renewable energies. We shall examine the extent to which $\mathrm{CO} 2$ emissions could be further reduced between 2030 and 2050. Since today already, nuclear power has the capacity to be a major actor in this reduction, we shall concentrate on its contribution, stressing once more that its role might be reduced thanks to the expansion of renewable energies. We shall examine the possible physical limitations on the increase of nuclear power considered, both in terms of reserves and in terms of the possible development of innovative reactors.

\section{2-PROJECTIONS UP TO 2030}

We have used scenario A2 of the IIASA ${ }^{4}$ as our reference. This scenario corresponds to a high growth rate and the preferential use of coal. It maximizes $\mathrm{CO} 2$ emissions, but, because of the limited oil and gas reserves it may be considered as the most likely scenario in the absence of strong action to curb $\mathrm{CO} 2$ emissions. It is close to "business as usual" and assumes market mechanisms. The IIASA scenarios follow the evolutions of economy and energy variables in 11 regions. To make things simpler we have grouped these regions into four aggregates: A)OECD, B)Transition Economies(former Soviet countries), C)Developing Asia (China, India, Southeast Asia), D)Rest of the world (South America, Africa, Middle East). In the reference scenario the share of nuclear power and renewable energies for electricity generation is small. We have considerably increased the nuclear share with different amounts depending upon the aggregate. However, we have kept these shares within what we think is reasonably achievable by 2030 , given the capabilities of the nuclear industry and the technological level of the different countries. We have replaced the reference shares of nuclear power for the production of electricity by:

\footnotetext{
ii Because it is capital intensive (a situation similar to that of renewables), and because of delayed capital return, nuclear power is at a disadvantage, especially as compared to a gas turbine combined cycle.

iii Scenario B of the IIASA/WEC Global Energy Perspectives 1998 report.

${ }^{\text {iv }}$ Scenario C2 of the IIASA/WEC Global Energy Perspectives 1998 report.
} 
- $\quad 85 \%$ rather than $14 \%$ for A. The proportion of nuclear power has been chosen so that the share of fossil fuels in the production of electricity becomes marginal.

- $50 \%$ rather $6 \%$ for $\mathrm{B}$. This relatively high value is justified by the high technical level of countries in transition.

- $30 \%$ rather than $3 \%$ for C. China and India already have strong nuclear capabilities.

- $30 \%$ rather than $0.1 \%$ for D. The D aggregate has a very inhomogeneous structure with countries like South Africa, Brazil, Argentina, Mexico and Chile which could achieve high levels of nuclearization and most of Africa which should remain weakly nuclearized. The Middle East could reach a significant level of nuclearization.

We have not modified the contribution of renewable energies, which reaches $18 \%$ of electricity production. Should they gain in competitivity, their contribution could partially replace nuclear power. Table 1 compares the structure of energy production and CO2 emissions in the reference and nuclear intensive scenarios.

It appears that, assuming 3000 additional reactors are built, as compared to the reference scenario, $\mathrm{CO} 2$ emissions would be reduced by $27 \%$, for a contribution of nuclear power to electricity production of $61 \%$.

Although significant, this result is insufficient. As stated above, temperature stabilization would require $\mathrm{CO} 2$ emissions below $3 \mathrm{Gt}$ Carbon equivalent, 4 times less than in the reference scenario, 3 times less than in the present modified scenario.

On line 18 of Table 1 we show CO2 emissions in the OECD. It is interesting to see that, in the nuclear intensive scenario, the emissions in 2030 are reduced to 1650 tons from the 3150 tons of 2000 . This means that fulfilling the Kyoto objectives would be easy in such a scenario.

\section{3-EXTRAPOLATIONS TO 2050}

\begin{tabular}{|c|c|c|c|c|c|c|c|}
\hline & & & World total & & & & \\
\hline 1 & 2 & 3 & 4 & 5 & 6 & 7 & 7 \\
\hline & IIASA(A2) & IIASA(A2) & Nuclear intensive & IIASA(A2) & Nuclear intensive & Hydrogen & IIASA(C2) \\
\hline 1 Year & 2000 & 2030 & 2030 & 2050 & 2050 & 2050 & $0 \quad 2050$ \\
\hline 2 Population(Millions) & 6168 & 8751 & 8751 & 10056 & 10056 & 10056 & 10056 \\
\hline $3 \mathrm{GDP}(\mathrm{G} \$)$ & 27436 & 61597 & 61597 & 101519 & 101519 & 101519 & 75050 \\
\hline 4 GDP/Capita k\$ & 4,4 & 7 & 7 & 10,1 & 10,1 & 10,1 & 7 \\
\hline 5 Primarv Enerav(Mtoe) & 10710 & 18408 & 18408 & 24840 & 24840 & 24840 & 14250 \\
\hline$\underline{6}$ Primary Electricity(Mtoe) & $\underline{4107}$ & 8060 & 8021 & 10231 & 10231 & 20154 & 6524 \\
\hline$\overline{7}$ Nuclear(Mtoe) & $\overline{493}$ & $\overline{684}$ & $\overline{4902}$ & 1092 & $\overline{7034}$ & $\overline{16047}$ & $\overline{2163}$ \\
\hline$\overline{8} \overline{\text { Fossil elec. }}$ & $3 \overline{008}$ & $5 \overline{894}$ & $\overline{1638}$ & $\overline{6409}$ & 467 & $\overline{1378}$ & $\overline{952}$ \\
\hline 9 Nuclear+renewables & 1099 & 2165 & 6383 & 3822 & 9764 & 18776 & 5573 \\
\hline $10 \%$ Electricity & $\underline{38,35}$ & 43,78 & $\underline{43,78}$ & $\underline{41,19}$ & $\underline{41,19}$ & $\underline{81,14}$ & $\underline{45,79}$ \\
\hline $11 \overline{\text { Nuclear \%El. }}$ & 12 & $\overline{8,49}$ & $\overline{61,12}$ & $\overline{10,68}$ & $\overline{68,75}$ & $\overline{79,62}$ & $\overline{33,15}$ \\
\hline 12 Renewable\% El. & 14,75 & 18,38 & 18,38 & 26,68 & 26,68 & 13,54 & $\underline{52,26}$ \\
\hline 13 Eossil elec.\% & 73.25 & 73.13 & 20.42 & 62.64 & 4.57 & 6.84 & $\overline{14.58}$ \\
\hline 14 Nuclear(Gwe) & 275 & $\underline{376}$ & 3387 & 607 & $\underline{4466}$ & 8915 & 1202 \\
\hline 15 Nuclear $(\%$ total $)$ & $\overline{4,6}$ & 3,72 & 26,63 & $\overline{4,4}$ & 28,32 & 64,6 & 15,18 \\
\hline $16 \mathrm{CO2}$ (Mt C) & $\underline{6976}$ & 11693 & $\underline{8465}$ & 16838 & 12695 & $\underline{5106}$ & $\underline{5114}$ \\
\hline 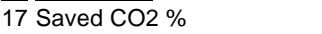 & & & $\overline{27,61}$ & & $\overline{24,61}$ & $\overline{69,68}$ & $\overline{69,63}$ \\
\hline $18 \mathrm{CO} 2(\mathrm{Mt} \mathrm{C})$ OECD & 3146 & 3973 & 1648 & 4266 & 2040 & 746 & \\
\hline 19 Unat tons/year & 31690 & 43983 & 315142 & 62414 & 401957 & 916951 & 115360 \\
\hline 20 Cumulative tons U nat & & $\underline{1,39 E+06}$ & $4,10 \mathrm{E}+06$ & $\underline{2,45 E+06}$ & $1,13 E+07$ & $\underline{1,64 \mathrm{E}+07}$ & $\underline{4,31 E+06}$ \\
\hline
\end{tabular}

TABLE 1

After 2030 further reductions should take place, such as:

- Phasing out of fossil fuel use for electricity production in favor of nuclear or renewable energies.

- Increase of the share of electricity in the energy mix: phasing out of fossil fuel use for home heating, increase of the share of electric public transportation, electric cars, hydrogen fuel cells etc.

A first nuclear intensive scenario, in 2050, is shown in column 6 of Table 1. It is a simple extrapolation of the nuclear intensive scenario in 2030 shown in column 4 . The high share of nuclear power in electricity production is generalized to all aggregates, with:

- $80 \%$ nuclear and $15 \%$ renewables for A.

- $80 \%$ nuclear and $17 \%$ renewables for $\mathrm{B}$.

- $60 \%$ nuclear and $36 \%$ renewables for $\mathrm{C}$.

- $\quad 40 \%$ nuclear and $53 \%$ renewables for D.

The share of electricity represents $41 \%$ of the primary energy. Although CO2 emissions are reduced significantly from $16 \mathrm{Gt}$ to $12 \mathrm{Gt}$, this reduction is not large enough to even come near the $3 \mathrm{Gt}$ goal. The relatively high share of renewables $(27 \%)$ had already gone part of the way in reducing $\mathrm{CO} 2$ emissions. Any further reduction of emissions requires a strong reduction of fossil fuels in the transportation and home heating sectors. We have 
assumed that, in the most developed countries, hydrogen fuel cells would be used extensively for private cars and the co-generation of heat and electricity. High temperature reactors would allow increased thermodynamic efficiencies as well as co-generation. These gains in efficiency are assumed to counterbalance the limited efficiency of hydrogen production, so that we have kept the total primary energy needs unchanged. The shares of electricity in the aggregates are as follows:

- $\quad 90 \%$ for A.

- $85 \%$ for B.

- $80 \%$ for C.

- $70 \%$ for D.

We find that, under these conditions, CO2 emissions are reduced below the year 2000 value, while the primary energy demand is multiplied by more than 3. With further electrification, a reduction of CO2 emissions below 3 Gt before 2070 becomes feasible. With these conditions, the CO2 concentration could be limited to 450 ppmv (i.e. twice the pre-industrial level) as seen on Figure 1 where the crosses correspond to the emissions of the nuclear intensive scenario in 2030 and to the hydrogen scenario in 2050 . This concentration corresponds to a temperature increase of approximately $2^{\circ} \mathrm{C}$ in 2100 .

The main characteristics of the scenario minimizing $\mathrm{CO} 2$ emissions are displayed on Figure 2.

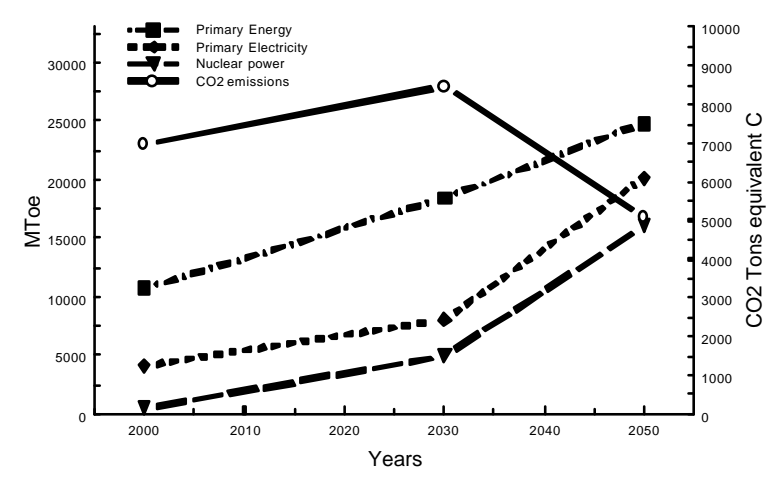

Figure 2 Least CO2 emission scenario: Primary Energy, total electricity and nuclear production (left scale MToe). The CO2 emission in $\mathrm{MT}(\mathrm{C})$ is also shown (right scale)

The results of scenario $\mathrm{C} 2$ of the IIASA are shown for comparison in column 8 of Table 1 . This scenario is the most efficient of the 6 IIASA scenarios in minimizing $\mathrm{CO} 2$ emissions. It is characterized by

- a modest GDP, $25 \%$ smaller than the A2 one

- a very low energy intensity such that the primary energy needs are $42 \%$ less than those of A2

- a less than $15 \%$ contribution of fossil fuels to electricity production. This is obtained by high shares of renewables $(52 \%)$ and nuclear power $(33 \%)$. Thus the philosophy of this scenario has a strong similarity with our "nuclear intensive scenarios" in minimizing the contribution of fossil fuels to electricity production. As we have already stressed, the relative shares of nuclear and renewables are not essential and should be determined by their relative competitivity.

Should the two strategies of lowering the primary energy demand and increasing the share of electricity be compatible, the $3 \mathrm{Gt}$ goal might be achieved as soon as 2050 .

\section{4-REQUIREMENTS FOR THE NUCLEAR POWER SYSTEM.}

The annual nuclear power production in the different scenarios is shown on line 7 of Table 1 . The 2030 nuclear intensive scenario produces 4902 MTOE, while the 2050 hydrogen scenario produces 16047 MTOE. The nominal nuclear power needed for these productions depends upon the mean to peak power ratio. This ratio usually decreases with the share of nuclear power, which is more efficiently used in the base regime. For this reason we have used mean to peak ratios varying between 0.6 and 0.8 . In the hydrogen scenario, reactors can be used to produce hydrogen outside peak demand periods, so that mean to peak ratios are improved. Note that this would hold for renewable energies as well. With these considerations the installed nuclear power need would be 3387 and $8915 \mathrm{GWe}$ in the nuclear intensive 2030 and hydrogen 2050 scenarios. The average number of diverging 
reactors would be around 150 annually in the period between 2010 and 2030 and would increase to approximately 300 annually between 2030 and 2050 .

\section{4-1-Natural Uranium Availability}

If carried out with PWR or BWR reactors, the important nuclear power deployment will make heavy demands on natural Uranium resources. Resources are, presently, estimated to be around 20 Million tons. Assuming PWR or BWR reactors, the cumulative needs in 2050 could reach 16 million tons. This shows that breeding reactors are necessary to meet the needs or, alternately, that Uranium would have to be extracted from sea water, at a significant cost.

\section{4-2-Breeding Scheme}

We consider two possible breeding cycles:

- The U-Pu cycle using fast reactors

- The Th-U cycle using thermal reactors

In both cases the initial loads are assumed to be mixtures of the fertile element (U or Th) with Plutonium taken from the used fuels of PWR and BWR reactors. It is important to make sure that the amounts of Plutonium available would be sufficient to supply all the breeding reactors by 2050 .

\section{4-2-1The U-Pu Cycle.}

Experience with fast breeders shows that a typical ${ }^{5} 1.2 \mathrm{GWe}$ reactor requires an initial inventory of 5 tons of Plutonium. A 1200 MWe reactor produces around 0.25 tons of Plutonium annually, corresponding to a doubling time of 20 years. However this value of the doubling time does not take into account the reprocessing stage. The longer the cooling time of the used fuel before reprocessing, the longer the effective doubling time. As an example, if the residence time of the Plutonium in the reactor is 4 years, and the cooling time also 4 years, the Plutonium inventory is doubled, as well as the doubling time. We study the transition between a PWR(BWR) based system to a fast reactor one. We assume that a strong PWR program starts in 2010, first breeders starting progressively in 2020. By 2030 no new PWRs diverge, leaving the field to fast reactors. Figure 3 shows the evolution of the reactor pool corresponding to a Plutonium production of $250 \mathrm{~kg} / \mathrm{GWe}$ by the PWRs and 200 $\mathrm{kg} / \mathrm{GWe}$ by the fast breeders. We assumed a cooling time of 1 year. The target of $9000 \mathrm{GWe}$ by 2050 can be reached. For longer cooling times it is found that the target cannot be reached. Cooling times as short as 1 year are probably not possible with standard aqueous reprocessing and would require pyro-chemical reprocessing. After 2050 the PWRs would be phased out progressively and the doubling time of the FR could be adjusted to the desirable evolution of the reactor pool. In the Figure we assumed a $1.5 \%$ annual increase of the nuclear pool.

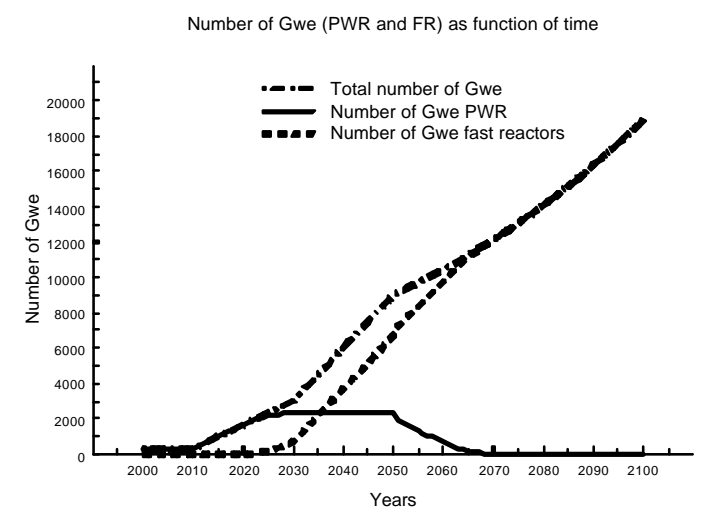

Figure 3: Number of GWe, for the U-Pu cycle, as a function of time 
Figure 4 shows the Plutonium stockpile outside the reactors. It displays three regimes: first the Pu inventory increases slowly until 2030 as a result of the production by the increasing PWR(BWR) pool. The decrease between 2030 and 2050 reflects the sharp increase in the number of fast reactors. The increase after 2050 is due to the slower increase of the number of fast reactors. Instead of keeping the total plutonium stockpile at such a high value, it could be possible to use the excess neutrons for the transmutation of fission fragments, for example. Alternately reactor sizes could be decreased, giving more flexibility to the power system.

In our scenario the last PWR reactors will be phased out in 2070. At that time the total amount of used natural Uranium would reach 12 million tons, close to the presently estimated reserves. This means that the number and life time of the PWR pool cannot be considered as an easily adjustable variable to achieve the strong increase of nuclear power between 2030 and 2050. This increase will be difficult to achieve and requires the early development of breeders, as well as the availability of as much as possible reprocessed Plutonium. The generalization of MOx incineration has to be weighed against this requirement. Similarly incinerating Plutonium in HTR reactors may be counterproductive if used fuel reprocessing is not possible. Until the development of breeder reactors the best use of reprocessing facilities might be the fabrication of Pu-Thorium fuels for PWRs, producing ${ }^{233} \mathrm{U}$, which could be used as described in 4-2-2.

Of course, accepting a lower value for the target in 2050 would make things easier. For example a target of 7000

GWe could be obtained with a doubling time of 32.5 years. Another possibility would be to increase the share of more efficient Plutonium producing reactors such as the CANDUs.

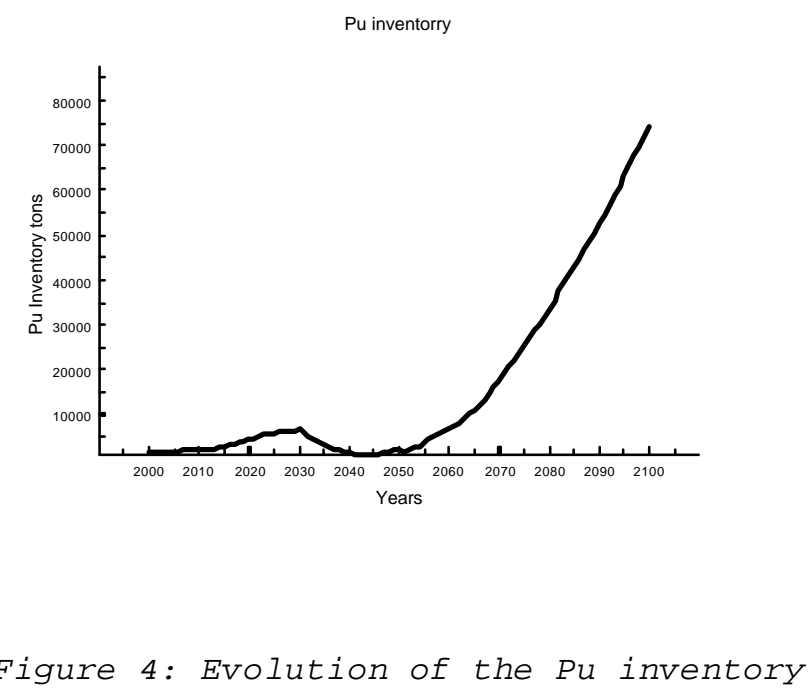

\section{4-2-2 The Th-U cycle}

The possibility of breeding ${ }^{233} \mathrm{U}$ from Thorium was demonstrated by the MSRE ${ }^{6}$ experiment. The MSBR ${ }^{7} \operatorname{project}$ has produced a rather detailed design for a large Molten Salt Reactor, with interesting breeding possibilities. As an alternative to the solid fuel U-Pu breeders we have studied the potential of the U-Th cycle with MSR reactors. The first fissile loads of the 1 GWe MSR are made of industrial Plutonium obtained from used PWR fuel reprocessing. Due to the mediocre neutronic properties of this Plutonium, our simulations show that 4 tons/GWe are needed to insure criticality ${ }^{\mathrm{v}}$. The initial Plutonium load is replaced by ${ }^{233} \mathrm{U}$. Every year, all 5 years old available Plutonium is used for new MSRs. This is not sufficient to insure the required rate of increase. The complement is obtained from the excess ${ }^{233} \mathrm{U}$ produced in the operating MSRs, used to start new Th-U3 reactors. Only 1 ton/GWe of ${ }^{233} \mathrm{U}$ is needed to insure criticality of a MSR. The doubling time is 25 years with a 10 day cycling time of the salt. The chemical treatment amounts to extracting fission products and Protactinium. ${ }^{233} \mathrm{U}$ is re-injected into the salt after Protactinium decay. Figure 5, is similar to Figure 3 for the U-Pu cycle, and shows the evolution of the reactor pool. We have distinguished $\mathrm{Th}-\mathrm{Pu}$ and Th-U3 reactors according to their initial loads. The life time of the reactors was assumed to be 40 years, which explains the decrease of the "Th-Pu" reactors after 2070.

\footnotetext{
$\mathrm{v}$ The equality between this number and the inventory of the U-Pu breeders is fortuitous
} 


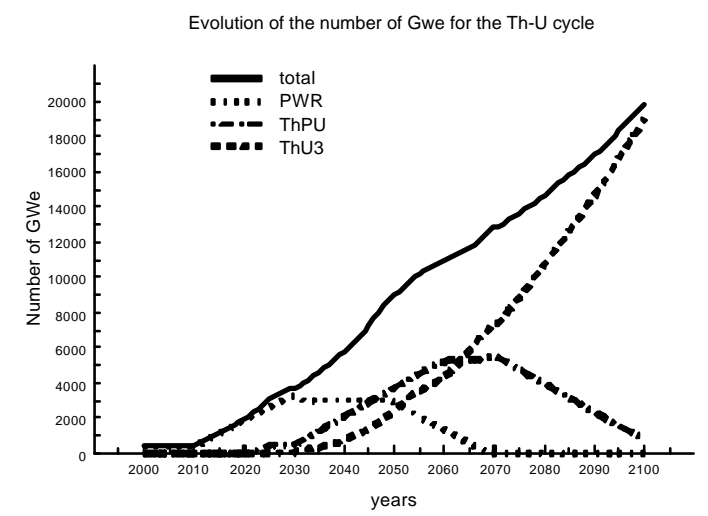

Figure 5 Number of GWe for the Th-U cycle as a function of time

Figure 6 shows the evolution of the ${ }^{233} \mathrm{U}$ stockpile outside the reactors. The Plutonium stockpile is not displayed since all produced Plutonium is, after 5 years cooling, used for new Th-Pu reactors. Like for the U-Pu cycle, the amount of available ${ }^{233} \mathrm{U}$ measures the flexibility of the system which could be used for fission product transmutation or(and) use of smaller production units. It is interesting to note that the final stockpile of ${ }^{233} \mathrm{U}$ is only 16000 tons, to be compared to the much larger stockpile of 80000 tons of Pu displayed on figure 4. However, due to the difference of inventories ( 1 ton versus 4 tons), the number of new reactors which could be fed with these stockpiles is the same, namely $16000 \mathrm{GWe}$. This illustrates the fact that the value of $\eta$ ( 2.9 for Pu versus 2.3 for ${ }^{233} \mathrm{U}$ ) is not the only relevant quantity to evaluate breeding potentials.

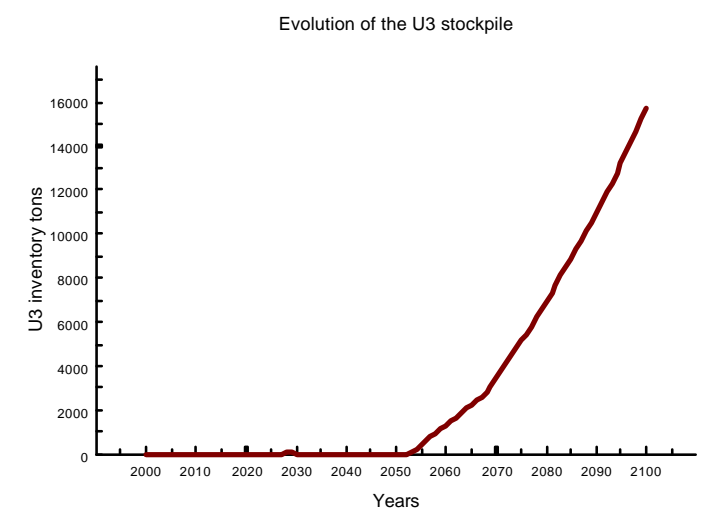

Figure 6 Evolution of the U3 stockpile in the Th-U scenario

\section{4-3 Safety Requirements}

The probability for an important radioactivity release following PWR core melting is currently estimated to be around $10^{-6}$. With the existing reactor pool such an accident might occur every 3000 years, or, in other words, with a probability of $3 \%$ in a century. For a $9000 \mathrm{GWe}$ reactor pool, and without safety improvements, this major accident might occur every century. This would, clearly, be unacceptable. The EPR is a first step in the right direction and may be compatible with the larger pool. Future breeder reactors, too, must have very high safety standards. In this respect, high temperature gas reactors, molten salt reactors and Accelerator Driven Sub-critical Reactors appear to be promising, especially for limited sizes.

In order to inforce the necessary high safety standards, it might be desirable to set up a World Nuclear Safety Authority in charge of reactor licensing and with the authority to suspend the operation of dangerous facilities. 


\section{4-4 Reprocessing Needs}

One has to distinguish reprocessing the fuel of the PWR from that of the breeders. The size of the PWR pool will reach $3000 \mathrm{GWe}$. This will produce, annually, 90000 tons of used fuels to be reprocessed, most probably in centralized facilities like those of La Hague and Sellafield.

Reprocessing is a necessity for the breeders and converters. Most probably, reprocessing will be associated locally to the breeders and converters, using pyrochemical techniques.

It has been proposed not to reprocess high duty ceramic fuels such as those of high temperature gas reactors. In absence of reprocessing, after the fuel is burnt up it has to be replaced by a new fuel produced in another type of reactor or by enriched Uranium. Thus, breeding from the fertile part is not be possible.

\section{4-5 Waste Production}

Although the considerable increase of the size of the reactor pool will lead to an ample production of fission products, the characteristics of the breeding pool have several interesting consequences:

- Plutonium becomes a fuel. It also seems possible that most of the minor actinides will be incinerated.

- By 2050 about 10 million tons of depleted Uranium will be available. These could provide a $10000 \mathrm{GWe}$ U-Pu breeding pool with fuel for 1000 years. Alternately, in the case of the Th-U cycle only a modest amount of 10000 tons of Thorium would be needed annually.

- Aside from technological wastes, fission products will be produced at an annual rate of 10000 tons.

\section{4-6 Capital Needs}

Assuming the capital cost of a $1 \mathrm{GWe}$ nuclear facility between 1 and 1.5 billion $\$$, the cumulative investments needed would amount to between 10 and 15 trillion $\$$ in the period 2010-2050. This is to be compared to the cumulative investments estimated, in scenario A2, to 18 trillion \$ between 2020 and 2050.

\section{5-CONCLUSION}

Large hydroelectric and nuclear power plants are the only proven, both economically and technologically, techniques able to replace fossil fuels in the production of electricity. The development of hydroelectricity is limited by severe environmental constraints. Thus, nuclear power is, at present, the only realistic possibility to reduce $\mathrm{CO} 2$ emissions while providing more available energy to developing countries. In a probably distant future new forms of renewable energies could concur with nuclear power to curb $\mathrm{CO} 2$ emissions. Meanwhile it is wise to push the nuclear contribution to its limit. We find that, even for high energy intensity scenarios, intensive use of nuclear power could reduce the $\mathrm{CO} 2$ emissions to less than $3 \mathrm{Gt} \mathrm{C}$ as early as 2070, limiting the temperature rise to about $2^{\circ} \mathrm{C}$. in 2100 . In the scenario which allows this performance $150 \mathrm{GWe}$ PWR reactors would be built annually starting in 2010, the total number of PWRs stabilizing between 2500 and $3000 \mathrm{GWe}$ in 2030. Breeders using either the fast U-Pu or the thermal Th-U cycles would develop from 2020 on to reach $6000 \mathrm{GWe}$ in 2050. With such deployment, fossil fuels could be excluded from electricity production while the share of electricity in primary energy would rise to more than $80 \%$, from the present $40 \%$. This increase of the share of electricity could be obtained by a general use of hydrogen and of heat co-generation.

In this nuclear intensive scenario a large fraction of presently estimated Natural Uranium reserves will be used. The increase of the breeder pool appears to be the fastest possible and will put strain on the management of Plutonium as well as on the sizes of the reactors. Relaxing the timing conditions, increasing the share of renewable energies or decreasing the energy intensity would, of course, alleviate this strain.

\section{REFERENCE}

${ }^{1}$ IPCC $3{ }^{\text {rd }}$ assessment report 2000

2 "Climate Change, the science of climate change", GIEC 1995,Technical summary B.9.2

${ }^{3}$ M.Charpin, B.Dessus, R.Pellat, "Étude économique prospective de la filière électrique nucléaire”, Commissariat au Plan. Paris. 2000.

${ }^{4}$ IIASA/WEC Global Energy Perspectives 1998 report.

${ }^{5}$ J.Bussac et P.Reuss, Traité de Neutronique Ed.Hermann 1985

6 P.N.Haubenreich et al., Experience with the Molten Salt Reactor Experiment, Nuclear Applications and Technology, vol.8(1970)118 
7 M.W.Rosenthal et al., Molten-Salt Reactors history, status, and potential, Nuclear Applications and Technology, vol.8(1970)107 